\title{
ESTIMATE OF CHARLSON COMORBIDITY INDEX, FRAX FRACTURE RISK AND TOTAL CARDIOVASCULAR RISK ON THE SCORE SCALE IN PATIENTS WITH CHRONIC OBSTRUCTIVE PULMONARY DISEASE WITH REDUCED NUTRITIONAL STATUS
}

\author{
Kochetova E.V. ${ }^{1}$ \\ ${ }^{1}$ Petrozavodsk State University, Petrozavodsk,e-mail: 67011@mail.ru
}

Aims.

The aim of this study was to investigate the bone mineral density (BMD), the risk of osteoporotic fractures per the FRAX programme, Charlson comorbidity index, and total cardiovascular risk (TCVR) on the SCORE scale in patients with chronic obstructive pulmonary disease (COPD) with reduced nutritional status.

Materials and methods.

The study included 245 COPD patients. Weight deficit was detected in $12.65 \%$ of patients with COPD in the study group. COPD patients with reduced nutritional status were examined for bone mineral density (BMD) and the risk of osteoporotic fractures per the FRAX programme. Total cardiovascular risk (TCVR) was also estimated on the SCORE scale.

Results.

The lowest parameters of bone mineral density of the lumbar spine were characteristic for patients with COPD stage 4 with reduced nutritional status (BMD $0.71 \pm 0.02 \mathrm{~g} / \mathrm{cm}^{2}$ for $\mathrm{L1}, 0.79 \pm 0.06 \mathrm{~g} / \mathrm{cm}^{2}$ for $\mathrm{L2}, 0.87 \pm 0.08 \mathrm{~g} / \mathrm{cm}^{2}$ for $\mathrm{L3}, 0.88 \pm 0.1 \mathrm{~g} / \mathrm{cm}^{2}$ for $\mathrm{L4}$ ). Bone mineral density of the femoral neck was also reduced in patients with COPD stage 4. In COPD stage 4, femoral neck BMD was $0.63 \pm 0.12 \mathrm{~g} / \mathrm{cm}^{2}$. High absolute risk of femoral neck fracture was detected in $66.7 \%$ of patients with COPD with weight deficit. Overall for the group, Charlson comorbidity index in the group of COPD patients with low nutritional status was $4.53 \pm 1.03$ points. A very high cardiovascular risk was detected in 53.3\% of patients with COPD and low nutritional status. A high cardiovascular risk was noted in $20 \%$ of patients with COPD and weight deficit.

Conclusions.

Conclusion: COPD patients with reduced nutritional status have a significant comorbid background both in terms of cardiovascular complications, and osteoporosis and related risk of osteoporotic fractures.

Keywords: COPD, bone mineral density, osteoporotic fracture risk, FRAX, Charlson comorbidity index, total cardiovascular risk, SCORE.

\section{INTRODUCTION.}

The Global Initiative for Chronic Obstructive Lung Disease (GOLD) 2018 report interprets chronic obstructive pulmonary disease (COPD) as a disease with diverse comorbidities [1]. COPD has multiple manifestations (osteoporosis, hypertension, heart failure, arrhythmia, depression, lung cancer, GERD, diabetes mellitus, etc.) [1]. The GOLD concept regards a COPD patient as multimorbid [1].

Comorbid clusters in COPD phenotypes help rationally assess the contribution of comorbidities to a COPD patient's prognosis. Burgel et al. ran hierarchical cluster analysis of more than 500 patients' data and identified three major groups: Phenotype I was described as COPD with a minimal comorbidity background; Phenotype II featured a high comorbidity risk of severe emphysema but lower incidence of cardiovascular diseases and low BMI; Phenotype III was associated with high fatality, mainly due to the high incidence of cardiovascular diseases, albeit with lower emphysema [2].

These three phenotypes are of undoubtedly great practical interest. Due to its minimal comorbidity background, Phenotype I is the most favorable one; the patient's prognosis will solely depend on the progression of respiratory disorders, in particular, bronchial obstruction. 
Phenotype II (the low-BMI one) is quite common. On the other hand, clinicians often fail to assess it adequately due to the seemingly favorable comorbidity background, as cardiovascular and sundry risks are mainly associated with obesity.

The emphysema phenotype is often associated with osteoporosis. This makes fracture risk evaluation relevant.

FRAX [3] is a recognized universal fracture diagnosis method, as it can evaluate the 10-year fracture risk for patients aged 40 to 90 [3]. FRAX screening is recommended for all postmenopausal women as well as for all men aged 50 or older [4].

Objective assessment of the comorbid status is extremely important and involves the use of unified scales and indices that could be effectively applied in clinical practice. The Charlson Comorbidity Index (CCI) is of interest in this regard [5]. Since cardiovascular events have a great impact on the long-term prognosis for COPD patients, total cardiovascular risk (TCVR) remains relevant. TCVR ranges from $>1 \%$ to $5 \%$ on average; $>5 \%$ to $10 \%$ is considered high; $>10 \%$ is considered very high [6]. By convention, the obesity-associated COPD phenotype is considered to be one of severe cardiovascular risks; cardiovascular risk for COPD patients with a lower nutritional status remains an open question. It is of interest to study the comorbidity background in COPD patients with a lower nutritional status, i.e. to study the comorbidity index as well as the comorbid foci not included in the CCI, mainly osteoporosis.

The goal hereof was to estimate the mineral density of bones, the risk of osteoporotic fractures by FRAX, the Charlson Comorbidity Index, and the TCVR in weight-deficient COPD patients.

MATERIALS AND METHODS. Two hundred forty-five COPD patients were examined. The study covered a sample spanning from 2007 to 2018. COPD diagnosis used the GOLD 2009 classification. A MasterLab/Jaeger unit was used for pulmonary function testing (PFT).

The research team ran general body plethysmography and used the CCI [5]. Bone mineral density (BMD) tests were performed on a Lunar DPX-NT unit. Osteoporotic fractures were analyzed by FRAX. SCORE was used to define the TCVR. The research results were processed on an IBMcompatible PC with a Pentium CPU using Microsoft Office Excel 2003 and Statistica 6.0. Means and standard deviations were computed for normally distributed features $(\mathrm{M} \pm \mathrm{s}$, where $\mathrm{M}$ is the arithmetic mean, $\mathrm{s}$ is the standard deviation); the median and the interquartile range were found for non-Gaussian distributions $(\mathrm{A}(\mathrm{L}-\mathrm{H})$, where $\mathrm{A}$ is the median, $\mathrm{L}$ is the lower quartile, $\mathrm{H}$ is the upper quartile). Statistical analysis used non-parametric statistics: the Kruskal-Wallis ANOVA test for 3 or more independent samples, the Mann-Whitney test for two independent samples, the Wilcoxon test for 2 dependent samples, and Spearman's correlation test (Rebrova, 2003). 
RESULTS. In the total sample, $12.65 \%$ of the patients were diagnosed as underweight. A lower nutritional status was significantly more frequent in Stage 4 COPD patients: $26.5 \%$, cf. 6.2\% of Stage 2 COPD patients $(\mathrm{p}<0.05)$. Table 1 presents the characteristics of COPD patients with a lower nutritional status.

Table 1

Characteristics of COPD patients with a lower nutritional status

\begin{tabular}{|l|c|c|c|}
\hline Indicator & $\begin{array}{c}\text { Stage 2 COPD, } \\
\mathrm{N}=6\end{array}$ & $\begin{array}{c}\text { Stage 3 COPD, } \\
\mathrm{N}=16\end{array}$ & $\begin{array}{c}\text { Stage 4 COPD, } \\
\mathrm{N}=9\end{array}$ \\
\hline Men/women & $6 / 0$ & $15 / 1$ & $9 / 0$ \\
\hline $\begin{array}{l}\text { Average age } \\
\text { years })\end{array}$ & $56.67 \pm 5.09$ & $64.94 \pm 6.57$ & $61.56 \pm 8.67$ \\
\hline $\begin{array}{l}\text { BMI, kg/m }{ }^{2} \\
\text { Smoking index }\end{array}$ & $17.18 \pm 0.92$ & $16.75 \pm 1.12$ & $16.09 \pm 1.45$ \\
\hline $\begin{array}{l}\text { Tobacco exposure, } \\
\text { pack-years }\end{array}$ & $40(240-240)$ & $240(240-240)$ & $360(240-480)$ \\
\hline
\end{tabular}

COPD patients with a lower nutritional status were aged $61.06 \pm 7.49$ on average; $96.8 \%$ of them were men. The tobacco exposure of Stage 2, 3, and 4 COPD patients was 41 (40-47), 41 (4050) and 51.5 (41-67.5) pack-years, respectively.

The bone mineral density (BMD) of the lumbar spine in COPD patients with a lower nutritional status degraded progressively as COPD progressed. Thus, the bone mineral density of the lumbar spine in the $\mathrm{L}_{1}-\mathrm{L}_{4}$ zone in Stage 2 COPD patients was $0.86 \pm 0.19 \mathrm{~g} / \mathrm{cm}^{2}$ for $\mathrm{L}_{1}$, $0.95 \pm 0.22 \mathrm{~g} / \mathrm{cm}^{2}$ for $\mathrm{L}_{2}, 1.04 \pm 0.28 \mathrm{~g} / \mathrm{cm}^{2}$ for $\mathrm{L}_{3}, 1.07 \pm 0.34 \mathrm{~g} / \mathrm{cm}^{2}$ for $\mathrm{L}_{4}$, see Table 2. Underweight Stage 3 COPD patients had the following lumbar-spine BMD: $0.86 \pm 0.17 \mathrm{~g} / \mathrm{cm}^{2}$ for $\mathrm{L}_{1}$, $0.94 \pm 0.19 \mathrm{~g} / \mathrm{cm}^{2}$ for $\mathrm{L}_{2}, 0.99 \pm 0.2 \mathrm{~g} / \mathrm{cm}^{2}$ for $\mathrm{L}_{3}, 1.0 \pm 0.15 \mathrm{~g} / \mathrm{cm}^{2}$ for $\mathrm{L}_{4}$, see Table 3. Stage 4 patients of the same cohort had the lowest bone mineral densities $(\mathrm{p}<0.05)$. Lumbar-spine BMD was as follows: $0.71 \pm 0.02 \mathrm{~g} / \mathrm{cm}^{2}$ for $\mathrm{L}_{1}, 0.79 \pm 0.06 \mathrm{~g} / \mathrm{cm}^{2}$ for $\mathrm{L}_{2}, 0.87 \pm 0.08 \mathrm{~g} / \mathrm{cm}^{2}$ for $\mathrm{L}_{3}, 0.88 \pm 0.1 \mathrm{~g} / \mathrm{cm}^{2}$ for $\mathrm{L}_{4}$, see Table 4.

Stage 2 to 4 COPD patients with a lower nutritional status also differed in terms of femoral neck BMD. BMD equaled $0.77 \pm 0.04 \mathrm{~g} / \mathrm{cm}^{2}$ in Stage 2 patients, $0.73 \pm 0.1 \mathrm{~g} / \mathrm{cm}^{2}$ in Stage 3 patients, and $0.63 \pm 0.12 \mathrm{~g} / \mathrm{cm}^{2}$ in Stage 4 patients. The proximal hip had a BMD of $0.88 \pm 0.05 \mathrm{~g} / \mathrm{cm}^{2}$ in Stage 2 patients, $0.84 \pm 0.13 \mathrm{~g} / \mathrm{cm}^{2}$ in Stage 3 patients, and $0.7 \pm 0.1 \mathrm{~g} / \mathrm{cm}^{2}$ in Stage 4 patients. Thus, Stage 4 COPD patients with a lower nutritional status differed significantly from their Stage 2 counterparts in terms of $\mathrm{BMD}, \mathrm{p}<0.05$. 


\begin{tabular}{|l|c|}
\hline Studied region & $\mathrm{BMD}, \mathrm{g} / \mathrm{cm}^{2}$ \\
\hline Lumbar spine $\mathrm{L}_{1} \mathrm{BMD}, \mathrm{g} / \mathrm{cm}^{2}$ & $0.86 \pm 0.19$ \\
\hline Lumbar spine $\mathrm{L}_{2} \mathrm{BMD}, \mathrm{g} / \mathrm{cm}^{2}$ & $0.95 \pm 0.22$ \\
\hline Lumbar spine $\mathrm{L}_{3} \mathrm{BMD}, \mathrm{g} / \mathrm{cm}^{2}$ & $1.04 \pm 0.28$ \\
\hline Lumbar spine $\mathrm{L} 4 \mathrm{BMD}, \mathrm{g} / \mathrm{cm}^{2}$ & $1.07 \pm 0.34$ \\
\hline Ward's triangle BMD, g/cm & $0.63 \pm 0.04$ \\
\hline Trochanter BMD, g/cm & $0.8 \pm 0.07$ \\
\hline Proximal hip as a whole, BMD, g/cm ${ }^{2}$ & $0.88 \pm 0.05$ \\
\hline Femoral neck BMD, g/cm & $0.77 \pm 0.04$ \\
\hline
\end{tabular}

Table 3

BMD in Stage 3 COPD patients with a lower nutritional status

\begin{tabular}{|l|c|}
\hline Studied region & BMD, g/cm \\
\hline Lumbar spine L1 BMD, g/cm ${ }^{2}$ & $0.86 \pm 0.17$ \\
\hline Lumbar spine L2 BMD, g/cm ${ }^{2}$ & $0.94 \pm 0.19$ \\
\hline Lumbar spine L3 BMD, g/cm ${ }^{2}$ & $0.99 \pm 0.2$ \\
\hline Lumbar spine L4 BMD, g/cm ${ }^{2}$ & $1.0 \pm 0.15$ \\
\hline Ward's triangle BMD, g/cm ${ }^{2}$ & $0.54 \pm 0.15$ \\
\hline Trochanter BMD, g/cm ${ }^{2}$ & $0.77 \pm 0.12$ \\
\hline Proximal hip as a whole, BMD, g/cm ${ }^{2}$ & $0.84 \pm 0.13$ \\
\hline Femoral neck & $0.73 \pm 0.1$ \\
\hline BMD, g/cm ${ }^{2}$ & \\
\hline
\end{tabular}

Table 4

BMD in Stage 4 COPD patients with lower nutritional status

\begin{tabular}{|l|c|}
\hline Studied region & BMD, g/cm ${ }^{2}$ \\
\hline Lumbar spine $\mathrm{L}_{1} \mathrm{BMD}, \mathrm{g} / \mathrm{cm}^{2}$ & $0.71 \pm 0.02$ \\
\hline Lumbar spine L2 BMD, g/cm ${ }^{2}$ & $0.79 \pm 0.06$ \\
\hline Lumbar spine L3 BMD, g/cm ${ }^{2}$ & $0.87 \pm 0.08$ \\
\hline Lumbar spine L4 BMD, g/cm ${ }^{2}$ & $0.88 \pm 0.1$ \\
\hline Ward's triangle BMD, g/cm ${ }^{2}$ & $0.56 \pm 0.12$ \\
\hline Trochanter BMD, g/cm ${ }^{2}$ & $0.65 \pm 0.06$ \\
\hline Proximal hip as a whole, BMD, g/cm ${ }^{2}$ & $0.7 \pm 0.1$ \\
\hline Femoral neck BMD, g/cm & $0.63 \pm 0.12$ \\
\hline
\end{tabular}


(2.4 to 9.6) for Stage 3 COPD patients, and 6.4 (3.2 to 18) for Stage 4 COPD patients, see Table 5.

Table 5

FRAX fracture risks for COPD patients with a lower nutritional status

\begin{tabular}{|l|c|c|c|}
\hline Studied region & Stage 2 COPD & Stage 3 COPD & Stage 4 COPD \\
\hline Femoral neck & $3.0(2.8-3.2)$ & $6.0(2.4-9.6)^{*}$ & $6.4(3.2-18)$ \\
\hline
\end{tabular}

Note: $* \mathrm{p}<0.05$.

Compared to Stage 2 COPD patients (Table 5), FRAX-computed femoral neck fracture risk was significantly higher for Stage 3 and Stage 4 patients, $\mathrm{p}<0.05$. A high absolute femoral neck fracture risk is a serious threat to the patients' health. COPD patients with a BMI $<18.5$ tended to be at high risk of femoral neck fracture (FRAX>3). Of the underweight COPD patients, 66.7\% belonged to that category. CCI was the highest in underweight Stage 4 COPD patients at 5.17 \pm 1.72 (3.5 \pm 0.58 and $4.93 \pm 0.79$ in Stage 2 and Stage 3 patients, respectively).

Overall, CCI averaged $4.53 \pm 1.03$ for the sample. The SCORE total cardiovascular risk for COPD patients with a BMI $<18.5$ was very high for $53.3 \%$ of the sample, high for $20 \%$ of the sample.

Literature suggests body weight loss in COPD patients is a manifestation of the systemic inflammatory effect [7]. The prognosis for underweight COPD patients depends not only on the emphysema typical for this subgroup. The emphysema phenotype was complicated by reduced bone mineral density and associated osteoporotic fractures. The emphysema-osteoporosis association involves common bone and lung destruction mechanisms [2]. In this research, the COPD patients with a lower nutritional status had lower bone mineral density. This symptom was most pronounced in Stage 4 patients. The comorbidity background of the underweight COPD patients was very high and complicated by a very high cardiovascular risk for $53.34 \%$ of the cohort.

\section{CONCLUSIONS.}

1. COPD patients with lower nutritional status generally had an extremely unfavorable multifactorial comorbid model that comprised osteoporosis, as well as a high risk of cardiovascular pathology.

2. The lower nutritional status phenotype of COPD patients was associated with a very high cardiovascular risk for $53.3 \%$ of the patients and a high risk for $20 \%$ of the patients.

3. Stage 4 patients of the same cohort had the lowest bone mineral densities. The femoral neck fracture risk was also found to be the highest for underweight Stage 4 COPD patients. 


\section{REFERENCES}

1. Global Initiative for chronic obstructive lung disease 2018. Available at: https://goldcopd.org/ (accessed 15 October 2019).

2. Burgel P.R., Paillasseur J.L., Peene B. et al. Two distinct chronic obstructive pulmonary disease (COPD) phenotypes are associated with high risk of mortality. PLoS One, 2012, vol. 7, no 12, p.51048, doi 10.1371/journal.pone.0051048

3. Kanis J.A., Johnell O, Oden A. et al. FRAX ${ }^{\mathrm{TM}}$ and the assessment of fracture probability in men and women from the UK. Osteoporosis International. 2008. vol.19, no 4, pp.385- 397, doi 10.1007/s00198-007-0543-5.

4. Clinical recommendations. Osteoporosis [Klinicheskie rekomendatsii. Osteoporoz]. Available at: https://www.endocrincentr.ru/sites/default/files/specialists/science/clinic-

recomendations/rec_osteoporosis_2016.pdf (accessed 12 October 2019).

5. Charlson M.E., Pompei P., Ales K.L. et al. A new method of classifying prognostic comorbidity in longitudinal studies: development and validation. Journal of Chronic Diseases, 1987, vol. 40, no 5, pp 373-383, doi 10.1016/0021-9681(87)90171-8

6. Cardiovascular prevention. National recommendations Available at: https://medi.ru/info/5953/ (accessed 15 October 2019).

7. Kolpakova A.F, Burgart T.V., Maksimov N.G. Loss of body weight as a manifestation of systemic inflammation effect in chronic obstructive pulmonary disease [Poteria massy tela kak proiavlenie sistemnogo effekta vospaleniia pri khronicheskoi obstruktivnoi bolezni legkikh]. The Siberian Medical Journal - Sibirskij medicinskij zurnal 2007, no 6, pp. 48-50. 